\title{
Oliver Gußmann
}

\section{Das Priesterverständnis des Flavius Josephus}

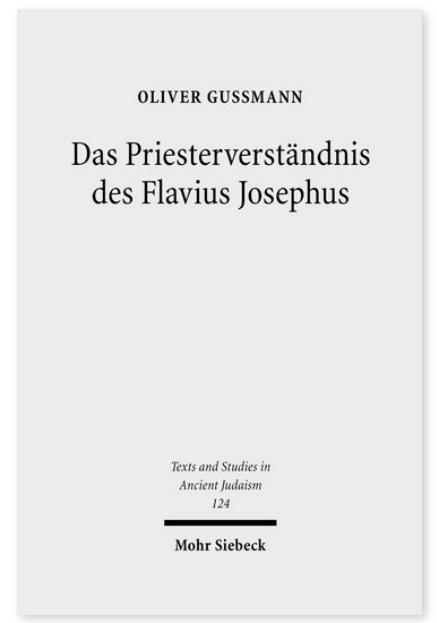

2008. XIV, 514 Seiten (+ 2 Abb.). TSAJ 124

ISBN 978-3-16-151457-9

DOI 10.1628/978-3-16-151457-9

eBook PDF 179,00€

ISBN 978-3-16-149562-5

Leinen $179,00 €$
Die Gestalt des antiken jüdischen Historikers Flavius Josephus erschließt sich am homogensten von seiner Priesterschaft und von seinem Priesterverständnis her, nicht aber durch seine Zuordnung zu einer der politisch-religiösen Parteien. Die Hohenpriester sind wesentliche Protagonisten der Geschichtsschreibung des Josephus. Er selbst ordnet sich dem hasmonäischen Priesteradel zu und sucht die Nähe zur politischen Macht. Josephus beruft sich auf seinen Status als Priester auch ohne aktive Kultausübung. Dieser Status ist zuerst und unverlierbar in seiner priesterlichen Abstammung begründet. Josephus orientiert seine Sicht gegenüber römischen Lesern häufig an kultischen Gesichtspunkten sowie am Status und der Funktion von Priestern.

Oliver Gußmann untersucht die Bedeutung der hohenpriesterlichen Amtsnachfolge und Genealogie bei Josephus, die Verbindung von Priestertum und Prophetie und das Modell eines jüdischen Gemeinwesens, das Josephus als Theokratie versteht. Josephus stellt die Jerusalemer Tempelarchitektur und den Ornat des Hohenpriesters mit Detailkenntnissen dar und deutet sie symbolisch. Die Hohenpriestergewänder kommunizieren nicht nur politische Botschaften gegenüber den Römern nach außen, sondern sie ordnen auch die jüdische Gesellschaft nach innen und haben kultisch mit den Vorstellungen von Reinheit und Sühne des Volkes und der Ordnung der Schöpfung zu tun. Damit leistet Oliver Gußmann einen Beitrag zur Josephusforschung und zur Erhellung der religiös-kulturellen Vorstellungswelt des antiken Judentums im ersten Jahrhundert n. Chr.

Diese Arbeit wurde mit dem Adolf-Schlatter-Preis zur Förderung christlicher Theologie des Jahres 2009 ausgezeichnet

Oliver Gußmann Geboren 1963; Studium der Theologie in Neuendettelsau, Wien, Bonn, Erlangen und Jerusalem; 2007 Promotion; derzeit Touristenpfarrer an St. Jakob, Rothenburg ob der Tauber; Lehrbeauftragter für Antikes Judentum am Institut für Neues Testament an der Universität Erlangen-Nürnberg.

Jetzt bestellen:

https://mohrsiebeck.com/buch/das-priesterverstaendnis-des-flavius-josephus-9783161514579?no_cache=1

order@mohrsiebeck.com

Telefon: +49 (0)7071-923-17

Telefax: +49 (0)7071-51104 